\title{
Urban Texas Teacher Retention: Unbelievable Empirical Factors Tied to Urban Teacher Persistence and Retention
}

\author{
LaSonya Moore ${ }^{1}$, Kara Rosenblatt ${ }^{2}$, Kevin Badgett ${ }^{3}$, James Eldridge ${ }^{4}$ \\ University of South Florida St. Petersburgl, University of Texas of the Permian Basin ${ }^{2}$ \\ University of Texas of the Permian Basin ${ }^{3}$, University of Texas of the Permian Basin ${ }^{4}$ \\ United States of America
}

\begin{abstract}
Teacher turnover in urban high-poverty schools is detrimental to students' achievement. In fact, one of the most prevalent social justice issues today is the unequal distribution of experienced teachers to urban high-poverty schools. Researchers suggest that experienced teachers are more effective at raising student performance than new or early career teachers, thereby ensuring their students are equipped for life after high school. Unfortunately, teachers leaving the field is an oft-cited challenge for school leaders. This is true across the nation and has been described as a great challenge for urban districts in Texas where the teacher attrition rate is twice the national average. Decades of research on the topic suggests that workplace conditions, effective school leadership, professional support, and a culture of high expectations are inextricably tied to teacher retention in urban settings. However, Texas is a unique state with a range of resources and landscapes. Of the 1,200 independent school districts, 11 (less than 1\%) are considered major urban districts. And yet, the 11 major urban districts employ almost 61,500 teachers (17.4\% of the state teaching population) and work in 1,400 schools (16\% of Texas schools). The purpose of this study was to identify factors empirically tied to teacher retention in the 11 major urban districts in Texas. Using a nonexperimental, retrospective research design, the authors collected and analyzed district-level data from the 2014-2015 Texas Academic Performance Report to identify specific factors that significantly contributed to teacher retention in urban Texas districts. The regression model identified four significant factors that contributed to the retention of urban teachers in Texas (district special education participation percentage, district teacher tenure average, new teachers, and percentage of students identified as at-risk). The findings suggest that higher percentages of special education and at-risk students contributed to retention while new teachers and average teacher tenure contributed to teacher attrition. Given the important role teachers play in student achievement, districts and campus leaders should continually consider new ways to develop,
\end{abstract}

equip and retain urban teachers. Furthermore, this empirical research sheds light on previously unidentified factors that were found to influence teacher attrition and retention in urban school districts in Texas. Therefore, additional research in which districts and campus leaders continue to examine the relevance and effect of the factors identified in this study is needed to understand how these implications can potentially be generalized to other urban districts to support urban teacher retention and student achievement.

\section{Introduction}

Since 1989, the national teacher attrition rate in the United States has increased 50\% and remains steady at approximately $8 \%$ [1]. In Texas, teachers leave the classroom annually at $16.6 \%$ [2], twice the national average. In 2012, schools across the nation lost 238,000 teachers due to attrition, essentially equal to the demand for the following school year. Teacher attrition is also a great area of concern for those teachers who are new to the field. Researchers cite teacher attrition rates between $19 \%$ and $30 \%$ within the first five years of teaching [3], [4], [5], [6], [7]. As the number of newly hired teachers has increased over the last decade; the high attrition rate has significantly and negatively impacted the teaching labor market including students' educational experiences [1], [4], [6], [7].

At the organizational level, the most frequently cited reasons for teachers leaving, regardless of their years of service in the field, stem from workplace dissatisfaction (55\%) [8], [9], [10]. Workplace conditions have a large impact on the teacher turnover rate; and researchers commonly find attrition linked to instructional leadership, school culture, collegial relationships, common planning time/collaboration, teachers' decision-making input, professional development resources, facilities, and lack of parental support and involvement [11], [12].

With these challenges, it is important that policy makers and school leaders become proactive in their efforts to staff their schools. However, armed with 
knowledge of teachers' impact on learning, accountability issues, and the need to prepare students for success in a global economy, the educational system cannot sacrifice teacher quality by simply filling vacancies with warm bodies. Rather, factors that determine how to preserve teacher quality and affect teacher retention and long-term employment must be explored. To address these issues, the primary purpose of this study was to identify specific factors that impact teacher retention within urban Texas school districts.

\section{Theoretical Context}

\subsection{Urban Educators}

One of the most prevalent social issues in the United States today is the unequal distribution of quality teachers to urban, high-poverty schools. Teachers who work in urban, low-income, high minority schools experience higher rates of attrition than their colleagues in urban areas with low rates of poverty [13].

The success of any school depends on its ability to retain its experienced teachers [14]. However, there is no consensus as to how to retain quality educators in high-poverty, urban schools. Researchers suggest that teacher retention may be influenced by factors outside the classroom such as increased stress associated with multiple professional roles and organizational factors [13], [15]. For example, Moore Johnson and colleagues [16] studied how working conditions predict job satisfaction and career plans for a sample of more than 25,000 teachers in more than 1,140 schools in the United States [16]. The results of their report, Project on the Next Generation of Teachers, showed that urban schools suffered from higher rates of teacher turnover than those in rural and suburban areas. Additionally, the organizational factors of the urban schools in the study played a large role in whether teachers chose to leave their posts [16].

\subsection{History}

Historically, teacher retention has been an expensive and severe issue that has become increasingly more important when viewed through the lens of accountability and academic achievement as defined by Every Student Succeeds Act of 2017 [17]. Teacher attrition is estimated to costs the United States up to $\$ 2.2$ billion annually [17], [18]. Based on a nationwide survey of public administrators, school board members listed teacher retention as the most severe issue due to the closely related rigorous expectations of NCLB and lack of support at the federal level [19], [20]. Many teachers believed that the accountability requirements and barriers beyond their control associated with NCLB undermined them as educators and placed them in a difficult professional position, thereby impacting their decisions to stay or leave the education profession [19], [20], [21] one example would be the evaluation process [17], [18], [22].

Regardless of the educators' positions, urban schools have been losing their best teachers in massive numbers [12], [23]. Decades of research has indicated that acquiring and retaining high quality teachers in urban settings is challenging; to acquire and retain a sufficient number of highly qualified teachers in urban settings is nearly unquantifiable [21], [24]. Public perceptions that suggest urban schools and teachers who serve predominantly poor students of color are failing may also weigh heavily on teachers' decisions to stay or leave the field [24], [25], [26]. In an effort to dismantle some of the historical educational inequities of NCLB, President Obama signed Every Student Succeeds Act (ESSA) into law [4], [17].

\subsection{The Need for Effective Educators}

The loss of effective teachers has a significant impact on student achievement [23]. Retention rates in the United States have continued to decline [17], [21], [24], [25]. These factors place urban students of color and students with exceptionalities at an even higher risk of academic failure [24]. The No Child Left behind Act [NCLB] was a landmark reform reauthorizing the Elementary and Secondary Education Act [ESEA] of 1965 [17]. NCLB was one of the most ambitious federal efforts to raise student achievement in the last four decades [18]. The intent behind NCLB was to close achievement gaps among students who belong to minority groups, have disabilities, are economically disadvantaged or have limited English proficiency [17]. NCLB became a powerful force in the lives of educators, and NCLB proponents failed to anticipate the impact that the Act would have on teacher retention [18].

NCLB significantly affected the recruitment and retention of effective teachers. The retention process is complex, particularly in urban schools where a large percentage of the population are students of color and students with exceptional needs [17], [18], [19], [20]. The National Commission on Teaching and America's Future (2003) and the National Education Association (2003) report that the 21 st century teaching force is the largest in history with the most stringent accountability measures, making it even more difficult for teachers to remain in urban highpoverty, low-performing schools [25]. Teachers in high-poverty, low-performing urban schools often feel marginalized by school reform efforts that do not take into account the numerous barriers faced by teachers in challenging urban educational settings [4]. December 10, 2015, President Obama took a major progressive stance towards equity in education by 
replacing the controversial NCLB with ESSA. Stayers may consider teaching to be the "best of times" [4] (p. 1); leavers may consider teaching to be the "worst of times" (p.1) due to the past two decades of political change and education reform [4]. President Barack Obama had a strong commitment to improving education efforts, and this has resulted in increased accountability measures with support [4]. We know highly effective teachers can have an enriching effect on the daily lives of students as well as their lifelong educational and career aspirations [22]. Based on the data, we also know empirically that effective teachers also have a direct influence on student growth and achievement [26], [27]. Years of research on teacher quality has shown that effective teachers not only demonstrate the importance of consistency, development and growth, but also the importance of relationships while increasing student achievement [8], [14], [15], [22].

\subsection{Retaining Special Educators}

Teaching is a complex profession with multiple contextual factors, requiring extensive skills and training for those who engage in the profession. As demographic trends change, so does the social distance between urban students and teachers [14], this is even more prominent for students with disabilities and special educators. Thus, in many instances, these demographic shifts tend to make the retention gap even wider [24], [25], [27]. Educators who desire to bridge the social dissonance and cultural gap understand the need to become culturally responsive [27], [28].

As of 2016, Texas serviced the ninth-lowest percentage of special education students in the nation. This is not due to lack of special education students and needed services, but the lack of state and district policy enforcement. Lawmakers at the Texas Capitol considered how to help students with disabilities in an effort to ensure states cannot force schools to turn away students who need special education services [28], [29]. With the passing of Senate Bill 160 in 2017, banning once and for all, any limits on the number of students enrolled in special education. In 2013-2014 the average number of students serviced by Texas public school systems were 5153, 701.There were 631,389 African American students, 73,741 $(10.8222 \%)$ of those students receive special education services, English Language Learners (ELL) averaged 848,592 students, with 63,987 (7.5404\%) of those students receiving special education services, totaling 443,834 $(8.6119 \%)$ total students receiving ESE services, clearly disproportionality exits [28], [29], [30]. Therefore, creating an even greater need for effective special educators in urban settings.

The empirical data within this study clearly illustrates successful retention efforts relating to urban schools with a high rate of special education teachers.
Retention factors may contribute to increased teacher support [22], [28]. Keeping in mind, urban teacher supports vary drastically, many are unobservable, thereby limiting the knowledge, skills, and mindsets necessary to address the "true" realities of urban educators [10].

Texas data highlights educators that teach Special Education and At-Risk students, these teachers are more prone to persist in their current urban educational settings when they are working with our neediest populations. Nationwide, approximately 31 percent of special education students 14 years of age or older drop out each year. In Texas, only about 6 percent of special education students drop out. Therefore, urban educators teaching special education and At-Risk students are far more likely to stay in school and work toward a high school diploma than their counterparts across the nation [28], [29], [30].

This study has eluded to teachers who are selfefficacious in their ability to teach special education and at-risk students while remaining in an urban educational environment. Another possible explanation of teacher persistence in urban schools may be extracted from teachers' self-efficacy beliefs [31]. When teachers feel a sense of connectedness, commitment and preparedness their individual selfefficacy increases. When special education teachers' self-efficacy beliefs are recognized this results in their desire to persist in challenging urban classrooms [31]. Teachers that persist become committed to their students, colleagues, and communities they serve, many being products of the very community they now serve [31]. These strong, intrinsic, personal connections, create and internal desire to change, a desire to take a social justice stance, while bringing their own diverse backgrounds to the classroom to connect with their students while maintaining their personal identity [31]. Many urban schools in Texas are experiencing retention success in challenging urban school environments for various reasons. One successful strategy surrounds residential replication, when the residents are the teachers and therefore are now the educational experts. Subsequently the community beliefs about urban educators' desire to persist begin to change. Retaining special educators is not about recruitment, but retention [1], [6], [7], [13], [26]. Retaining effective special educators require organizational insight and awareness of the contextual factors that support teacher retention [31].

\subsection{Impactful School Characteristics}

Based on the empirical data from this study, context matters. Contextual factors matter most for urban educators. The importance of contextual factors surrounding educational organizations was first brought to light by Ingersoll [32]. Early research on the topic was based on the nationally representative School and Staffing Survey (SASS) dataset and its 
supplement, the Teacher Follow-up Survey (TFS). The TFS emphasizes the effects of teacher characteristics, school characteristics, and organizational conditions that lead to teacher turnover [29], [30], [31]. Ingersoll found that the absence of contextual factors pertaining to administrative support, peer-to-peer collegiality, and school culture were tied with higher rates of teacher turnover [23].

The need for organizational leaders to assure time for new special education teachers to collaborate with experienced teachers is a critical factor that has a positive impact on the new teachers' professional development. Teachers who work for organizations that offer continuous induction support and guidance with mentors are less likely to leave the teaching profession than those who do not have induction support and access to mentors [33], [34] [35], [36].

If teachers are to meet the needs of their students in the 21 st century, focus should be placed on high quality planning and studying various induction programs. Induction programs with multiple goals including building teacher knowledge and professional skills, promoting communication skills, avoiding teacher isolation while building upon strategies that encourage teachers to persist must take precedence [3], [5], [8]. Integrating new teachers in collaborative, supportive communities encourages dialogue that supports best practices while building a network that will enable new teachers to persist. Teachers that lack the strategies and ability to persist also feel a lack of teacher organizational support, including feelings of isolation, limited to no autonomy, minimal to no induction, mentoring, or collegial connections has often provided the impetus for teachers to leave urban educational settings [8], [33].

Teachers who teach in urban schools with high proportions of low income and challenging students were more inclined to leave teaching due to limited resources, poor collegiality, limited or no mentoring, and lack of student disciplinary support [12], [13].

In addition, researchers have shown that urban educators require a wide-range of supports but receive little to no induction and mentoring support. Effective induction and mentoring processes can reduce the stress and challenges that urban teachers experience [36]. Loeb, Darling-Hammond, \& Luczak revealed the relationship between beginning teachers' perceived stress, lack of learning opportunities and how organizational and student characteristics affect teachers' self-efficacy, ultimately influencing their desire to leave or stay [36].

New teachers, particularly special educators, too often lack the professional support and constructive dialogue necessary to make the successful transition from pre- to in-service teaching [37], [38]. The result is a staggering number of new teachers who vacate the profession in the first three to five years. One-third (33 percent) of current public-school teachers in the
United States do not expect to be teaching in K-12 schools five years from now [4], [5] [6] [10]. Special educators are one-fortieth (2.5 percent) more likely to leave when compared to other beginning teachers. [39], [40]. Further, researchers have shown that teacher retention is more connected to the induction and mentoring of the first teaching experience than to an individual's academic proficiency, making the necessity to support new teachers during the induction process very apparent [39], [40]. Enhancing the competence and performance of teachers who are already working in the neediest schools in the U.S. is vital; induction and mentoring programs have become even more necessary [41].

Researchers have indicated that most teachers report that they have limited contact with other urban professional educators, and few are committed to developing relationships that encourage collaboration and commitment due to lack of time and support. The lack of effective induction and mentoring processes in urban schools negatively affects urban teacher retention. Urban classroom teachers experience an increased need for mentoring and support [41], [42], [43]. Many districts fail to understand the importance of preparation programs for urban teachers.

Special educators who feel comfortable in urban environments appear to be much more supportive and sensitive to their students' and peer needs, and are, therefore, likely to be more collaborative and committed [14], [35], [37], [38].

\subsection{Time Tenure Transition}

One of the biggest education problems nationally and internationally is the number of teachers that leave the field before gaining an opportunity to truly experience the profession. Contrary to current research Texas urban school districts are experiencing growth in the area of teacher retention for our neediest populations [44], [45]. However, retaining early career teachers and tenured teachers remains a sense of urgency for urban schools. According to Texas Academic Performance Report new teachers that enter the field of education in urban settings find it difficult to persist [39], [40], [41], [46]. This study supports the notion of urban teacher retention and their desire to transition based on time in the profession [45]. As new teachers entered more teachers exited, as the average tenure of a district's teaching staff increased, the teacher turn-over rate increased. Researchers have found that many tenured teachers transition into lateral roles or administrative roles while novice teachers leave the field of education all together. The identification of these variables has allowed educational administrators and researchers a better opportunity to understand trends that are contrary to current beliefs, while continuing to make strides towards retention in urban educational environments. 


\subsection{Leveraging Leadership}

Although this study of empirical data affirmed findings in the extant literature, it also challenged the links between teacher retention. Research has shown, unless teaching quality and principal leadership improve significantly, lasting improvements in education are unlikely [43]. Researchers have shown that, for the past two decades, policy reforms have focused on standards and assessments. The central role of human capital, (i.e., teaching quality and how to cultivate and extend more broadly the expert performance of teachers and principals), has not been given a high priority. Research also emphatically suggests that unless there are talented teachers in every classroom and talented principals in every urban building, policy reform will not be realized [44]. In order to investigate the role of both the intentional and unintentional factors relating to retention, we explore the extent to which urban school leaders allocate monetary and human resources to support teacher retention. Leveraging funds in urban schools to ensure equity for all can be challenging, effective leaders, manage and monitor monetary resources to ensure all students and teachers are provided with the resources to support growth and continued success.

Leadership is a key factor when it comes to retaining quality teachers. Effective school leaders are instrumental in creating a culture of care focused on individual teacher growth and supporting improvements in student learning and achievement while equally creating an environment for empowerment, resourcefulness, and continuous improvement. The link among the quality of principals, caliber of teaching, and levels of student achievement is tightly connected. School leadership is a key factor when it comes to retaining quality teachers. This, in turn, profoundly influences improvements in student learning and overall academic achievement [8].

Moreover, increasingly evident in building a body of educational knowledge, is the positive relationship between time spent on organizational management tasks, such as hiring, budget allocation, and school effectiveness. What has increasingly become a nationwide focus is the critical importance of a principal's strength in one specific aspect of organization management: the hiring and retention of effective teachers and the counseling-out of ineffective teachers [3].

In a study that used cross-sectional administrative data from Pennsylvania, evidence was found suggesting that principals can affect student achievement through the teacher hiring process [45]. Principals who appointed teachers with high academic goals were rewarded with higher student academic gains. Effective principals, as defined by student achievement at schools during a principals' tenure, were better able to attract and retain more effective teachers as well as remove less-effective ones [45]. Effective principals understand the importance of building positive relationships between all stakeholders; while organizing and manage organizational tasks, such as hiring, budget allocation, and school effectiveness. Leveraging leadership supports has increasingly become a nationwide focus and is of critical importance when desiring to retain urban educators [22], [27], [45].

Urban special educators who perceived their principals' leadership behaviors as supportive were less stressed, more committed and less likely to leave the field, while urban special educators who perceived their principals' leadership behaviors as unsupportive exited the field [53]. Principals' leadership behaviors require examination to see if their behaviors are positively or negatively impacting teachers' desires to remain at their schools or leave [46], [53]. Teachers were also surveyed from southern K-12 public schools [46]. Findings suggested three recurring factors that influenced teachers' decisions to stay; student success, subject matter, and the art of teaching [46]. Three other factors that influenced teachers' decisions to leave were also identified: lack of administrative support, teacher workload, and student discipline [46]. Similar studies are evident in countries around the world. For example, in one study in Ghana whereas teachers were surveyed to examine teacher retention and attrition [46], [47]. Questionnaires were disseminated to a sample of 116 teachers in four different senior high schools. The survey results suggest that teachers would leave their schools if their salaries, conditions of service, class and school environment did not improve [47].

The importance of a quality teaching force is prominent throughout the literature on effective teaching. However, quality leadership is clearly a key component of effective schools and improving school outcomes. Researchers have attempted to uncover what effective principals do to improve school outcomes. Not surprisingly, crucial to improving school outcomes is the principal's role in aiding and monitoring the school's instructional program and developing a positive learning culture, as well as increasing the organization's culture of care and concern [44].

\subsection{Administrative Support}

Research on teacher retention literature has emphasized administrative support as the decisive factor needed to increase urban teacher retention [48]. Administrators, individuals that formally evaluate teachers and maintain a supervisory role within the educational setting. We must understand the critical role school-based administrators play in all aspects relating to teacher persistence and retention. 
Principals, assistant principals (also known as schoolbased administrators), superintendents and educational leaders need to be collaborative in their efforts to empower urban teachers to persist so as to dismantle the educational achievement gap for our neediest populations [31], [48], [49, [50].

Administrators who empower teachers as equal members in school-based decisions significantly increase a teacher's desire to persist. The record of teacher persistence and retention in urban schools is bleak and is made worse by the lack of organizational and school-based administrative support in urban schools. It is time for systemic change. It is time for increased communication, collaboration, and collegiality, the conquering cure $\left(\mathrm{C}^{3}\right)$ [31], [48], [49, [50].

Communication, collaboration and collegiality not only increases urban teachers' desire to remain; it creates opportunities for shared decision making relating to professional development, which in turn, significantly impacts a school-based administrators' desire to retain urban teachers, specifically special education teachers [31]. Urban teacher persistence is a key component for urban school districts' desire to maintain a contented educational workforce nationally and internationally [31].

\section{Methodological/Theoretical framework}

During the 2014-2015 school year, there were more than 8,500 schools in 1,200 school districts across Texas [51]. Of those 1,200 districts, 11 were categorized as Urban District Types and were used in this analysis. In order to enable the researchers to arrive at a better understanding of factors which contribute to teacher retention in urban districts in Texas, district level data were analyzed for each of those districts.

Table 1. Teacher Retention in Texas Urban Districts Beta Values and Correlational Information on Significant Factors*

\begin{tabular}{|c|c|c|c|c|c|}
\hline \multirow[t]{2}{*}{ Model } & \multicolumn{2}{|c|}{$\begin{array}{l}\text { Unstandardized } \\
\text { Coefficients }\end{array}$} & \multirow{2}{*}{\multicolumn{2}{|c|}{$\begin{array}{c}\begin{array}{l}\text { Standardized } \\
\text { Coefficients }\end{array} \\
\text { Beta }\end{array}$}} & \multirow[t]{2}{*}{$\mathrm{t}$} \\
\hline & $\mathrm{B}$ & Std. & & & \\
\hline 5 (Constant) & -40.195 & 20.960 & & & -1.918 \\
\hline SPED* & -2.521 & .975 & -.757 & -2.587 & \\
\hline TENAVE** & 5.977 & 2.763 & 1.419 & 2.163 & \\
\hline FIRST5** & 1.961 & .589 & 2.507 & 3.331 & \\
\hline ATRISK* & -.668 & .274 & -1.681 & -2.435 & \\
\hline
\end{tabular}

This study used a non-experimental, retrospective research design. The primary purpose for the analysis of data collected in this study was to identify specific factors that impact teacher retention within urban Texas school districts. All data collected for this study were from the 2014-2015 Texas Academic Performance Report (TAPR) district-level reports. Data were analyzed using backward multiple regression techniques as found in the SPSS software. The backward multiple regression technique removes insignificant variables at each stage of the analysis to develop the most efficient regression equation, using only those variables that are significant. Significance for the model was set at $\mathrm{p}<0.05$.

The regression model identified four factors that make a significant contribution to the retention of teachers in urban district types in Texas. These factors included district special education participation percentage (SPED) rate for a district, teacher tenure average (TENAVE), new teachers (FIRST5), and the percentage of students identified as At Risk (ATRISK) ( $\mathrm{R}=0.948$; Adjusted R2=0.833; $\mathrm{p}=0.000$ ) (see Table 1 for the regression beta weights).

\section{Findings}

Two of the predictor variables had a negative relationship with the dependent variable. As the percentage of students participating in special education increased, the percentage of teachers who were leaving a district decreased. The second negatively related variable in the regression model was the percentage of a district's students identified as At Risk (for dropping out). As this population increased, the percentage of teachers leaving a district decreased. These findings were inconsistent with previous authors' findings for other settings and may be attributable in part to an increased scale of financial and human resources in large urban districts in Texas where funding is inclusive of monies tied to student enrollment and attendance.

Two of the predictor variables were also found to have a positive relationship with the dependent variable. The first was the percentage of teachers within their first five years in that role. As the percentage of a district's teachers within their first five years increased, the teacher turn-over rate increased. The final significantly contributing variable had a direct relationship with the dependent variable. As the average tenure of a district's teaching staff increased, the teacher turn-over rate also increased. In other words, as average experience in a district increased, teachers were less likely to stay with the district. Interestingly, this last piece is also inconsistent with previous authors' findings for other settings and may be attributable in part to experienced teachers' pursuit of professional opportunities in other district types (not urban). 


\section{Conclusion}

In conclusion, there are several of notable implications related to the findings of this study. Given the important role teachers play in student achievement, school districts and school-based administrators should be continually considering ways to teach, equip, and retain urban teachers. Urban teachers need to connect to the culture and climate of their school and students, specifically the neediest populations within the school setting, students in need of Special Education supports and students At Risk. The evidence is quite clear. Of the 11 urban school districts across Texas, the regression model identified four factors that made a significant contribution to urban teacher retention.

This research sheds light on factors that influence teacher turnover in urban school districts in Texas. Contrary to previous unpublished findings based on other district types, researchers found that an increase in At Risk and Special Education populations contributed to teacher retention. The authors believe this may be attributable to an increased pool of fiscal and human resources which can impact a school district's ability to support both teachers and students.

There are also implications pertaining to the impact of teacher experience on retention in urban school districts. Whereas the finding that the percentage of new teachers (within their first five years of experience) has a negative association with teacher retention was consistent with previous unpublished research by the authors, the finding that increased teacher experience also negatively contributes to teacher retention was inconsistent with that research. Both factors have implications for teacher "support" in urban districts. We know there are large gaps in urban, suburban and rural teacher retention, and we know that human capital has an enormous impact on teacher retention. We also know that policies that promote an investment in resources supporting teacher persistence and retention, lead to equity and a reduction in teacher attrition resulting in increased student achievement. When the cost of teacher turnover can be lowered these savings can then be used to support novice and veteran teacher retention efforts.

Finally, this research offers important empirical points for possible approaches to the challenge of urban teacher retention. By more effectively identifying factors that contribute to teacher retention and teacher turnover, school leaders can better ensure the cultivation of an environment where teachers stay and grow in their capacity to address the diverse needs of the students they serve.

\subsection{Implications}

There remains a historical and current disconnect between school-based administrators and teachers' due to minimal or no $\mathrm{C}^{3}$, for various reasons [31], [48], [50]. No matter how well an educational organization plans, failures of some sort are expected. Teachers need to feel valued and apart of the process while administrators need to feel a sense control within the overall process, both can be accomplished. One way to dismantle this observed gap is through the systematic implementation of $\mathrm{C}^{3}$ [31], [48]. The desired outcome is to develop teachers into educational professionals that are able to persist in urban learning environments. Thereby allowing administrators the opportunity to retain these educational professionals, $\mathrm{C}^{3}$ is key [31], [48]. School-based administrators are tasked to retain; however, teachers must desire to remain [31], [48].

\section{References}

[1] R.M. Ingersoll, L. Merrill, and D. Stuckey, Seven Trends: The Transformation of the Teaching Force, Updated April 2014, CPRE Report (\#RR-80), Consortium for Policy Research in Education, Philadelphia, 2014.

[2] Texas Education Agency, Overview of Texas Schools, Texas Education Agency, Austin, 2017.

[3] J. Cowan, D. Goldhaber, K. Hayes, and R. Theobold, Missing Elements in the Discussion of Teacher Shortages, American Institutes of Research, Washington. D.C., (2015).

[4] Darling-Hammond, L. (2009). President Obama and education: The possibility for dramatic improvements in teaching and learning. Harvard Educational Review, 79(2), 210-223.

[5] J. DeMonte, The Leaky Pipeline: Why Don't Teachers Return? American Institutes of Research, Washington, DC, (2016).

[6] R.M. Ingersoll, "Teacher Turnover and Teacher Shortages: An Organizational Analysis", American Educational Research Journal, American Educational Research Association, Washington, DC, 2001, pp. 499-534.

[7] R.M. Ingersoll, L. Merrill, and D. Stuckey, Seven Trends: The Transformation of the Teaching Force, Updated April 2014, CPRE Report (\#RR-80), Consortium for Policy Research in Education, Philadelphia, 2014.

[8] Darling-Hammond, L. (2003). Keeping good teachers: Why it matters, what leaders can do. Educational Leadership, 60(8), $6-13$.

[9] R.M. Ingersoll, L. Merrill, and D. Stuckey, Seven Trends: The Transformation of the Teaching Force, Updated April 2014, CPRE Report (\#RR-80), Consortium for Policy Research in Education, Philadelphia, 2014.

[10] The New Teacher Project, The Irreplaceables: Understanding the Real Retention Crisis in America's Urban Schools, Author, New York, 2012.

[11] A.B. Berry and M. Gravelle, "The Benefits and Challenges of Special Education Positions in Rural Settings: 
Listening to the Teachers", Rural Educator, National Rural Education Association, Chattanooga, 2013, pp.1-13.

[12] R.D. Gardner, "Should I Stay or Should I Go? Factors that Influence the Retention, Turnover, and Attrition of K12 Music Teachers in the United States", Arts Education Policy Review, Taylor \& Francis, Philadelphia, 2010, pp. 112-121.

[13] R.M. Ingersoll, "Teacher Turnover and Teacher Shortages: An Organizational Analysis", American Educational Research Journal, American Educational Research Association, Washington, 2001, pp.499-534.

[14] A.L. Lavigne, "Beginning Teachers Who Stay: Beliefs About Students", Teaching and Teacher Education, Elsevier, Chicago, 2014, pp. 31-43.

[15] C.F. Mansfield, S. Beltman, A. Price, and A McConney, "Don't Sweat the Small Stuff: Understanding Teacher Resilience at the Chalkface. Teaching and Teacher Education, Elsevier, Chicago, 2012, pp. 357-367.

[16] N.S. Simon, S.M. Johnson, S.K. Reinhorn, The Matchmaking Process: Teacher Hiring in Six Successful, High-Poverty, Urban Schools, The Project on the Next Generation of Teachers, Cambridge, 2015.

[17] No Child Left Behind Act of 2001, Pub. L. No. 107110, 115 Stat. 1425 (2002)

[18] Gay, G. (2007). The rhetoric and reality of NCLB. Race, Ethnicity And Education, 10, 279-293.

[19] Berry, B. (2004) Recruiting and retaining 'highly qualified teachers' for hard to staff schools. NASSP Bulletin, 88,5-27.

[20] Bowler, G. (2003, October 23). No child left behind: implications for rural school administrators and teachers. Paper presented at the NREA Conference, Kearney, Nebraska.

[21] Ingersoll, R.M., \& Perda, D. (2012). How high is teacher turnover and is it a problem? Philadelphia, PA: Consortium for Policy Research in Education, University of Pennsylvania.

[22] Alliance for Excellent Education, (2004). Tapping the potential: Retaining and developing high-quality new teachers. Washington, DC: Author.

[23] Boaler, J. (2003, March) When learning no longer matters: Standardized testing and the creation of inequality. Phi Delta Kappan, 84(7), 502-506.

[24] Ingersoll, R. r., Merrill, L. 1., \& May, H. h. (2016). Do Accountability Policies Push Teachers Out? Sanctions exacerbate the teacher turnover problem in low-performing schools--but giving teachers more classroom autonomy can help stem the flood. Educational Leadership, 73(8), 44-49.

[25] Boe, E. E., Barkanic, G., \& Leow, C. S. (1999) Retention and attrition of teachers at the school level: National trends and predictors (Data Analysis Report No. 1999- DAR1). Philadelphia: University of Pennsylvania,
Graduate School of Education, Center for Research and Evaluation in Social Policy.

[26] Ingersoll, R. M. (2001). Teacher turnover and teacher shortages: An organizational analysis. American Educational Research Journal, 38, 499-534.

[27] Jacob, B. A. (2007). The challenges of staffing urban schools with effective teachers. Future of Children, 17(1), 129-153.

[28] Valle-Riestra, D. M., Shealey, M. W., \& Cramer, E. D. (2011). Recruiting and Retaining Culturally Diverse Special Educators. Interdisciplinary Journal of Teaching And Learning, 1(2), 68-87.

[29] Rosenthal, B. M. (2018, Jan 12). Texas illegally excluded students from special education, officials say. New York Times Retrieved from https://search.proquest.com/docview/1986542015?accounti $\mathrm{d}=14745$

[30] Suydam, J. (2002). Special education students fare better in Texas; State dropout rate far below national average. The Austin American-Statesman (TX).

[31] Moore, L. L. (2016). Intrinsic and Extrinsic Motivators That Impac Teacher Retention in Challenging Urban Schools. Electronic Theses and Dissertations. 4944. http://stars.library.ucf.edu/etd/4944

[32] Ingersoll, R. M. (2001). Teacher turnover and teacher shortages: An organizational analysis. American Educational Research Journal, 38, 499-534.

[33] Downey, D. B., Von Hippel, P. T., \& Hughes, M. (2008). Are "failing" schools really failing? Using seasonal comparison to evaluate school effectiveness. Sociology of Education, 81, 242-270.

[34] Gay, G. (1990). Achieving educational equality through curriculum desegregation. Phi Delta Kappan, 72, 56-62.

[35] Gay, G. (2000). Culturally responsive teaching: Theory, research, and practice. New York, NY: Teachers College Press.

[36] Leko, M. M., \& Smith, S. W. (2010). Retaining Beginning Special Educators: What Should Administrators Know and Do?. Intervention In School And Clinic, 45(5), 321-325.

[37] Helms-Lorenz, M., Slof, B., Vermue, C. E., \& Canrinus, E. T. (2012). Beginning teachers' self-efficacy and stress and the supposed effects of induction arrangements. Educational Studies, 38(2), 189-207.

[38] Pedota, P. J. (2015). How Can Student Success Support Teacher Self-Efficacy and Retention?. Clearing House, 88(2), 54-61. doi:10.1080/00098655.2014.998600

[39] Texas Education Agency, Overview of Texas Schools, Texas Education Agency, Austin, 2017. 
[40] Percentage of Kids in special education by Texas education by Texas school district from 2003 to 2014 https://docs.google.com/spreadsheets/d/1ci0rJknVF8fSbsY E7zG5DRgX19jdo_fdyzVrR3DJL8/edit?usp=sharing Retrieved from https://www.houstonchronicle.com/denied/data/

[41] National Education Association. (2003). Status of the American public-school teacher,2000-2001. Washington, DC: National Education Association.

[42] Wilkins, E. A., \& Clift, R. T. (2007). Building a network of support for new teachers. Action in Teacher Education, 28(4), 25-35.

[43] Johnson, L. S. (2011). Targeted comprehensive induction for urban educators: An exploration of teacher motivation and retention. New Educator, 7(2), 131-152.

[44] Thibodeaux, A. K., Labat, M. B., Lee, D. E., \& Labat, C. A. (2015). The effects of leadership and high-stakes testing on teacher retention. Academy of Educational Leadership Journal, 19(1), 227-249. Retrieved from https://search.proquest.com/docview/1693219089?accounti $\mathrm{d}=14745$

[45] Sam, F. K., Effah, B., \& Osei-Owusu, B. (2014). Exploring issues of teacher retention and attrition in Ghana: A case study of public senior high schools in kwabre east district of ashanti region-ghana. Journal of Education and Practice, 5(1), 83-89

[46] U.S. Department of Education, National Center for Education Statistics. (2010). Teacher attrition and mobility: Results from the $2008-09$

Teacher Follow-up Survey (NCES 2010 - 353). Washington, DC: Author. Retrieved from http://nces.ed.gov/fastfacts/display.asp?id=28

[47] Consortium for Policy Research in, E. (2009). Taking Human Capital Seriously: Talented Teachers in Every Classroom, Talented Principals in Every School. Principals and Recommendations for Strategic Management of Human Capital in Public Education.

[48] Smith, T. M., \& Ingersoll, R. M. (2004). What are the effects of induction and mentoring on beginning teacher turnover? American Educational Research Journal, 41, 681714.

[49] Fulton, K., Burns, M., \& Goldenberg, L. (2005). Teachers learning in communities: The TLINC strategy. Phi Delta Kappan, 87, 298-305.

[50] Loeb, S., Darling-Hammond, L., \& Luczak, J. (2005). How teaching conditions predict teacher turnover in California schools. Peabody Journal of Education, 80(3), 44- 70.

[51] Texas Education Agency, Overview of Texas Schools, Texas Education Agency, Austin, 2017. 